\title{
The Effects of Building Openings on Airflow
}

\author{
(Case Study: Type 36 Low-Income Housing Unit) \\ Lestari*, Syaiful Muazir \\ Department of Architecture, Engineering Faculty \\ Universitas Tanjungpura \\ Pontianak, Indonesia \\ *lestari@teknik.untan.ac.id
}

\begin{abstract}
Airflow is a variable that affects indoor air quality, including health and comfort. It can be obtained by various aspects including openings in the building. This study aims to see how the openings in the type 36 housing unit affect the airflow in it. Type 36 housings are buildings intended for people with a low income wherein natural airflow is important to maintain health and comfort within the buildings. The pattern of air movement and the velocity of the airflow were studied. The method used was the computational fluid dynamics simulation. Several variables that affect airflow were observed, such as the position of the opening, opening conditions, and opening area. The results showed that the factor of the opening area is the most influencing factor for indoor airflow. Turbulence in the airflow reduces in the presence of more opening in the building.
\end{abstract}

Keywords-airflow, opening, air velocity, type 36 housing unit

\section{INTRODUCTION}

The type 36 house is the most sought-after type of house by the community in Indonesia. A type 36 house unit is a single landed house with an area of $36 \mathrm{~m} 2$. This type is a house is built within a limited area so that it can be affordable to people with a low income. The name is used because the building area is $36 \mathrm{~m} 2$, which is intended for four occupants. This area is based on the volume requirement for fresh air, which is $24 \mathrm{~m} 3$ per adult, so that with a minimum ceiling height of $2.7 \mathrm{~m}$, every $9 \mathrm{~m} 2$ can accommodate the needs of fresh air for one adult occupant. Generally, this building only consists of two bedrooms, one living room, and one bathroom. The living room is generally used as a multifunctional room, as a living room, family room, dining room, and for other activities.

Although the type 36 house has a limited area, the quality of the house remains a concern and must meet the health and comfort needs of the occupants. In low-cost residential buildings, attention to the quality of the physical elements of the environment can also be less, leading to the occupant feeling dissatisfied [1]. In fact, the quality of the indoor environment can affect the welfare and comfort of building occupants [2]. The design of a low-cost house, such as the type 36 house, should not neglect the quality of the environmental elements in the room, including the ventilation system that works in the building.
The air quality in type 36 houses, which are intended for low-income people, depends on the natural ventilation in a building. The ventilation system can affect the comfort and health of the residents of the building. The level of thermal comfort and fresh air change and the potential for the spread of pollutants in the room depend on ventilation. The movement of air in the room during the ventilation process can affect thermal comfort $[3,4]$. Thermal comfort requires uniform air flow and velocity [5]. In addition, the hourly rate of ventilation with low indoor fresh air exchange can increase the risk to health [6]. Airflow characteristics in the ventilation path can also affect the spread of pollutants in space [7]. The faster the air reaches the outlet, the more effective the ventilation system will be in removing pollutants [8]. The existence of obstructions that block the flow of air can reduce the performance of the ventilation in removing pollutants [9]. This is understandable because the shorter the time the pollutants are in space, the lower the possibility of occupants being exposed to pollutants. Therefore, the effectiveness of the ventilation system in type 36 houses, which can be learned from the airflow that occurs, can determine the comfort and health of the living.

Natural ventilation occurs due to airflow moving through the openings in the building. This airflow can be influenced by the opening factor in the building, including the type of window opening used [10]. The position where openings are placed in a building can also affect the airflow within it [11]. The design and placement of the openings have also been studied for their effects on the airflow characteristics. The window opening, which can be controlled by the angle of the opening, is considered advantageous because the required airflow characteristics can be adjusted according to the angle of the opening $[12,13]$. The aspect ratio of the length and width of the air inlet and outlet openings is another factor that affects air flow in dealing with indoor pollutants. The ratio between the length and width of the ventilation inlet showing the most effective performance is 4 [14]. These various factors can determine airflow to achieve effective ventilation as needed. Openings in buildings are important in the design and can significantly affect the airflow patterns within the building. 


\section{MethodolOGY}

The plan layout design in this study is a type 36 building unit, which was taken from secondary data. The design consists of two rooms located next to each other and one living room that extends from front to back. The living room is generally divided with furniture and functions as a family room, dining room, and kitchen. However, in this study, the condition of the house under study was unfurnished. Figures 1 and 2 show the building design type 36 used as a research case.

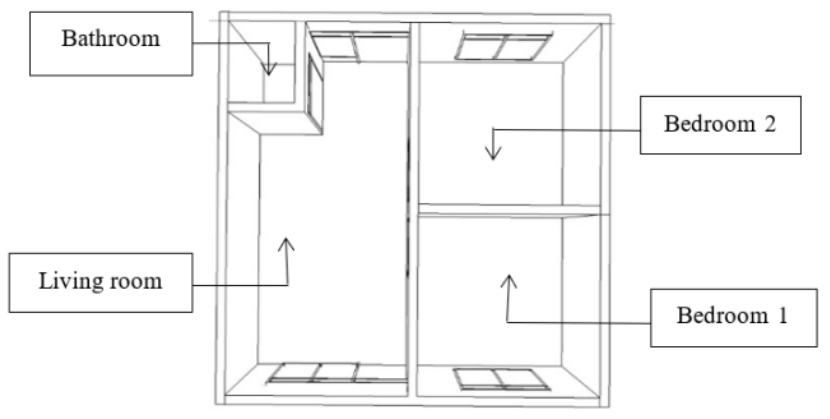

Fig. 1. Layout for opening position 1.

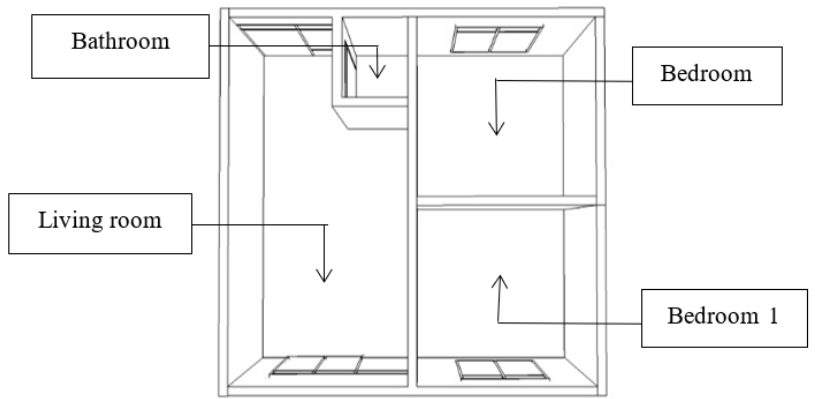

Fig. 2. Layout for opening position 2.
Some of the variables that affect the airflow were studied. The independent variables studied in this study were the layout and position of the openings, the conditions of the openings (open windows and closed windows), and the dimensions of the opening. A closed window condition means that the air flow only passes through the vent while an open window condition means that the air flow enters through the vent as well as the window. The dependent variable (dependent variable) is the airflow observed from the pattern, direction, and velocity of the air flow. Air flow conditions were studied through computational fluid dynamic (CFD) simulation by setting the values of other variables that affect the air flow to be uniform.

Wind speed through the inlet is set at a very low speed condition of $0.1 \mathrm{~m} / \mathrm{s}$, assuming that the housing conditions with houses built close to each other experience low air velocity. In addition, the condition of the air inside the building can also be studied when the outside airflow velocity conditions are slow. The results of the air flow simulation against the regulated conditions are then compared between one condition and another. The characteristics of airflow, its direction, and velocity inside the building are studied. Table 1 show the models simulation for this study.

TABLE I. MODELS SiMULATION

\begin{tabular}{|l|l|l|l|l|l|l|l|l|}
\hline & \multicolumn{1}{|c|}{ Model 1 } & \multicolumn{1}{|c|}{ Model 2 } & \multicolumn{1}{|c|}{ Model 3 } & \multicolumn{1}{c|}{ Model 4 } & \multicolumn{1}{c|}{ Model 5 } & \multicolumn{1}{c|}{ Model 6 } & \multicolumn{1}{c|}{ Model 7 } & \multicolumn{1}{c|}{ Model 8 } \\
\hline $\begin{array}{l}\text { Position of } \\
\text { opening }\end{array}$ & Position 1 & Position 1 & Position 1 & Position 1 & Position 2 & Position 2 & Position 2 & Position 2 \\
\hline $\begin{array}{l}\text { Window } \\
\text { dimensions } \\
(\mathrm{mxm})\end{array}$ & $1.25 \times 1.50$ & $1.25 \times 1.50$ & $1.50 \mathrm{x} 1.50$ & $1.50 \times 1.50$ & $1.25 \times 1.50$ & $1.25 \times 1.50$ & $1.50 \times 1.50$ & $1.50 \times 1.50$ \\
\hline $\begin{array}{l}\text { Vent } \\
\text { dimensions } \\
(\mathrm{mxm})\end{array}$ & $0.225 \times 1.50$ & $0.225 \times 1.50$ & $0.45 \times 1.50$ & $0.45 \times 1.50$ & $0.225 \times 1.50$ & $0.225 \times 1.50$ & $0.45 \times 1.50$ & $0.45 \times 1.50$ \\
\hline $\begin{array}{l}\text { Opening } \\
\text { conditions }\end{array}$ & closed window & open window & $\begin{array}{l}\text { Closed } \\
\text { window }\end{array}$ & open window & closed window & open window & $\begin{array}{l}\text { closed } \\
\text { window }\end{array}$ & open window \\
\hline
\end{tabular}

\section{RESULTS AND DISCUSSION}

The pattern of airflow, direction, and velocity that occurs in the type 36 house unit (shown in the following figure) is slice horizontally at a height of 1.4 meters. Figures 3 and 4 show the airflow with the layout of the opening position 1 with the bathroom position on the left side. Figure 3 represents a closed window condition while figure 4 an open window condition. From the two figures, it can be seen that the direction of air movement from the living room is divided into two, toward the outlet opening of the living room and the outlet opening of the bedroom 2. The airflow pattern from the inlet of the living room formed turbulent vortices before reaching the outlet. The simulation with closed windows showed that the vortices occur more when windows are open. The airflow pattern with many vortices causes the air in a room to stay for longer time. The longer the air containing pollutants is in the room, the more 
likely it is for the occupants to be exposed. The more turbulent vortices that occur in the reduced opening area conditions related to the results of the study that the reduced opening area results in higher pollutant concentrations [7] and the effectiveness of ventilation can be seen from how fast the air can reach the outlet [8].
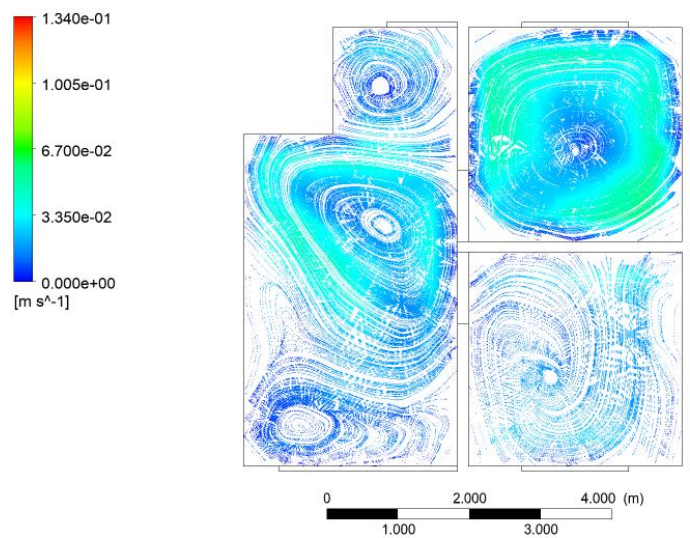

Fig. 3. The pattern of airflow, direction, and velocity of air on the condition of Model 1.
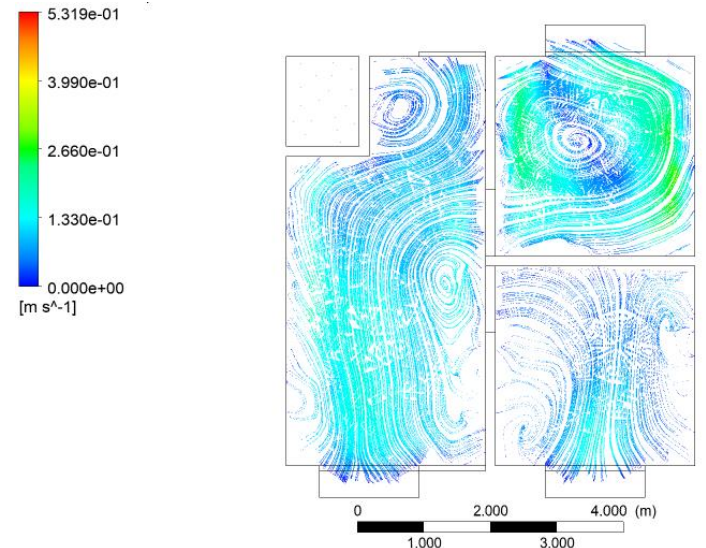

Fig. 4. The pattern of airflow, direction, and velocity of air on the condition of Model 2.

Figure 5 shows the flow, direction, and velocity of air with the dimensions of the opening widened and window closed. Figure 6 shows the flow, direction, and velocity of air with the dimensions of the opening widened and window open. Similar to the openings with dimensions of the smaller, airflow in the open windows can flow continuously to the outlet without experiencing many vortices. The airflow from the inlet of the living room to the outlet is also divided into two directions, mostly moving to the outlet of the living room and partly moving toward the outlet in bedroom 2 . The simulation with the closed window condition shows that the airflow also experiences vortices, but appears to be reduced compared to the smaller opening dimensions.
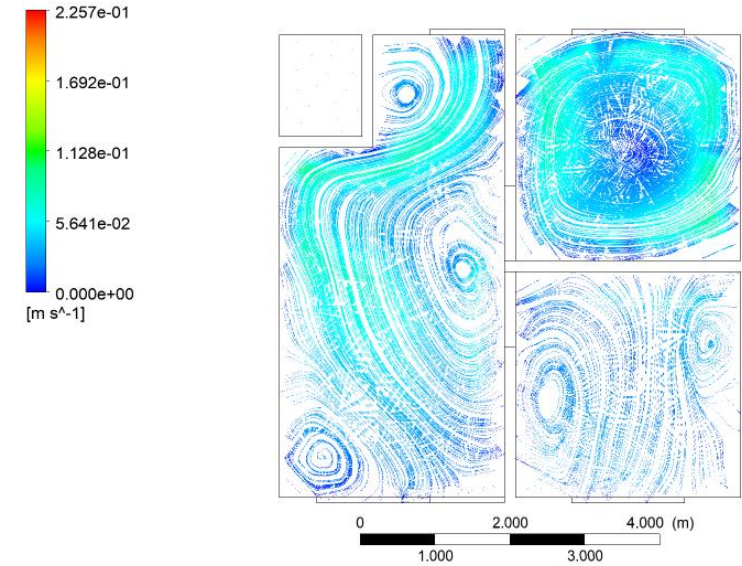

Fig. 5. The pattern of airflow, direction, and velocity of air on the condition of Model 3.
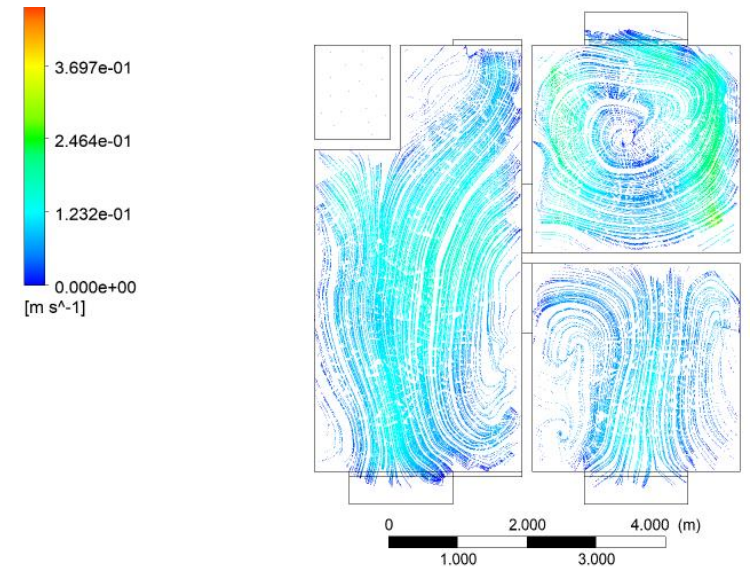

Fig. 6. The pattern of airflow, direction, and velocity of air on the condition of Model 4.

Figures 7, 8, 9 and 10 below are conditions where the room layout is changed with the bathroom in the middle. This change in layout causes changes in airflow patterns. Figure 7 shows the air movement pattern with a smaller opening dimension and the window closed, while figure 8 shows the simulation result with a smaller opening dimension with the window open. The pattern of air movement from the inlet of the living room tends to flow toward its outlet so that only a small amount of air moves into bedroom 2. Air from the inlet in bedroom 1 also tend to flow to the outlet openings of the living room so the air does not flow to the bedroom 2 . It can be understood that the airflow to the bedroom 2 is obstructed because of the bathroom wall in the middle of the room. Bathroom walls act as a barrier to airflow. Both conditions of the window, whether open or closed, produce a flow pattern with vortices before reaching the outlet. Turbulence vortices can occur in the airflow due to barriers [15]. The barrier can reduce the ventilation's performance in eliminating pollutants [9]. 

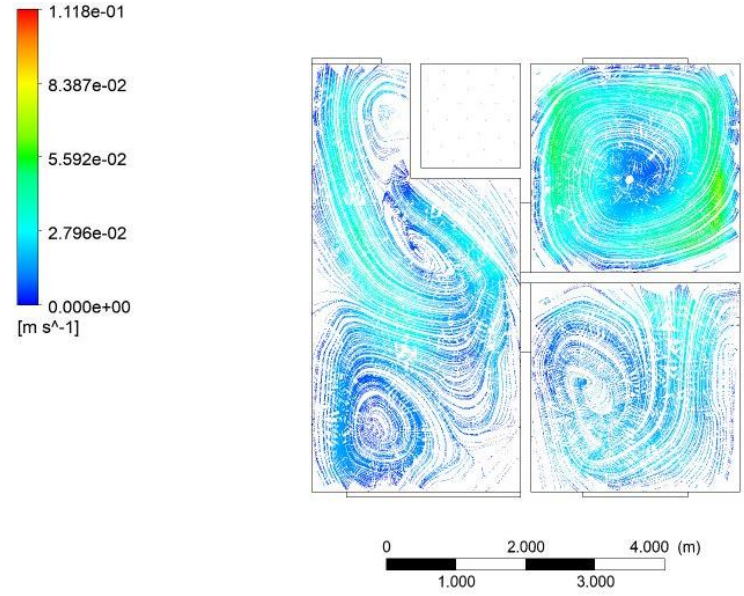

Fig. 7. The pattern of airflow, direction, and velocity of air on the condition of Model 5.
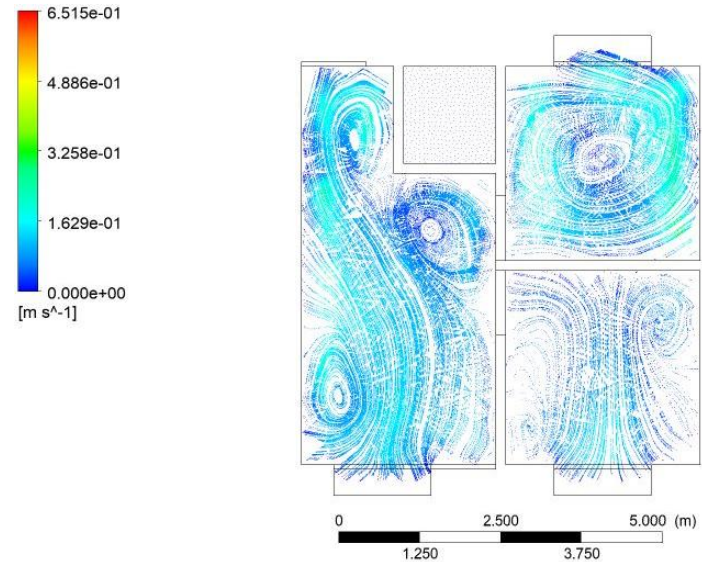

Fig. 8. The pattern of airflow, direction, and velocity of air on the condition of Model 6 .

Condition of the widened opening results in different airflow where some of the air flows to the opening of bedroom 2 (shown in figures 9 and 10). In the closed window condition, as shown in figure 9, the airflow to bedroom 2 comes from the inlet of the living room, which turns directions because it is blocked by the bathroom wall. In contrast, in the open window condition, as shown in figure 10, the airflow to bedroom 2 comes from the inlet in the bedroom 1 , which is blocked by the bathroom wall so that the direction turns to bedroom 2 .
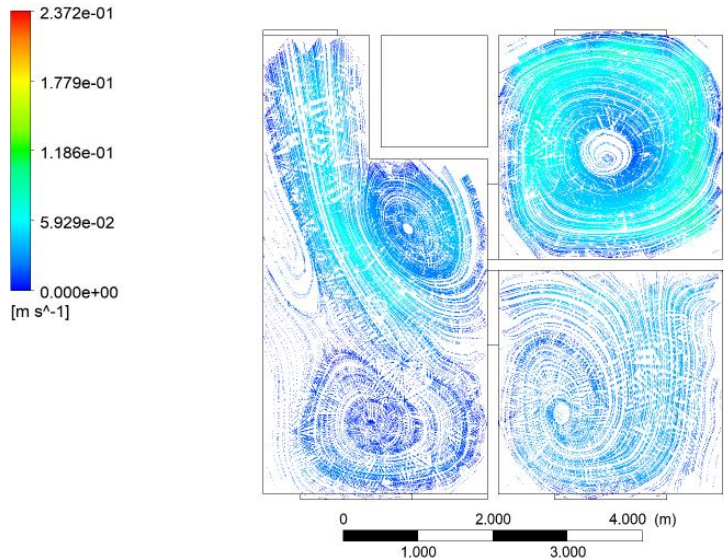

Fig. 9. The pattern of airflow, direction, and velocity of air on the condition of Model 5 .
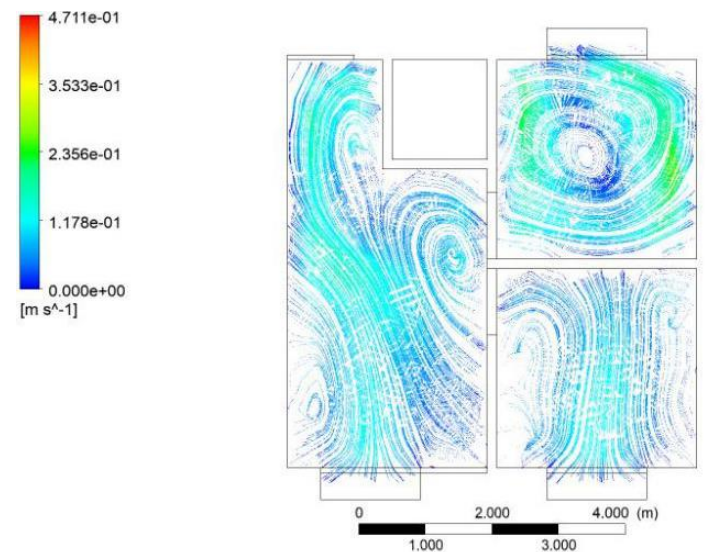

Fig. 10. The pattern of airflow, direction, and velocity of air on the condition of Model 6

The comparison of airflow velocities from various simulated models can be seen in figure 11. It can be seen that there is an increase in the minimum and maximum velocity of the airflow with changes in the dimensions of the opening, especially in the conditions of closed window openings (1-3 and 5-7). Previous study reported the same effect, a larger opening size results in a higher air velocity [16]. Meanwhile, when the window is open, the addition of the dimensions of the opening tends to decrease the air velocity in the room (2-4 and 6-8). Of all the simulated models, the open window condition shows an increase in air velocity almost four times compared to the closed window condition (1-2, 3-4, 5-6 and 7-8). The changes in layout and position of openings do not show a certain pattern of increase and decrease in airflow velocity. 


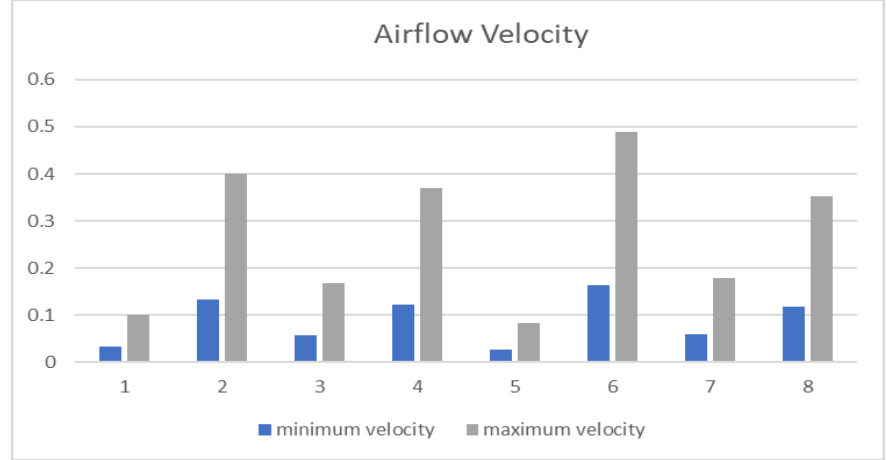

Fig. 11. Comparison of airflow velocity of various simulation models.

\section{CONCLUSION}

The small opening causes the airflow pattern to form turbulent vortices before reaching the outlet. These vortices can be detrimental if the air contains pollutants that must be removed immediately because the duration of the presence of a pollutant in the room extends. Expanding the opening through an opened window or enlarging the dimensions of the opening can reduce the presence of vortices in the room. The existence of a barrier in the room in the form of a bathroom wall located in the middle can also affect the direction of air movement. Enlarging the dimensions of the opening allows air to move to the outlet, thereby helping air to circulate in bedroom 2 .

A comfortable airflow velocity at $27^{\circ} \mathrm{C}$ can range from $0.3-0.9 \mathrm{~m} / \mathrm{s}$ [9]. The required flow velocity condition through simulations to the model can be achieved by opening a window or enlarging the dimensions of the opening. Enlarging the dimensions of the opening tends to accelerate the airflow when the window is closed or the airflow only passes through the vent; however, this actually causes air velocity to decrease when the window is opened.

\section{ACKNOWLEDGMENT}

This research was supported by the Engineering Faculty, Universitas Tanjungpura, Indonesia.

\section{REFERENCES}

[1] F. Ismail, I.L. Jabar, N.A.I. Janipha, and R. Razali, "Measuring the quality of life in low cost residential environment," Procedia - Soc. Behav. Sci. vol. 168, pp. 270-279, 2015.

[2] Y. Al horr, M. Arif, M. Katafygiotou, A. Mazroei, A. Kaushik, and E. Elsarrag, "Impact of indoor environmental quality on occupant wellbeing and comfort: A review of the literature," Int. J. Sustain. Built Environ., vol. 5, no. 1, pp. 1-11, 2016.

[3] N. Gong, K.W. Tham, A.K. Melikov, D.P. Wyon, S.C. Sekhar, and K.W. Cheong, "The acceptable air velocity range for local air movement in the tropics," HVAC R Res., vol. 12, no. 4, pp. 1065-76, 2006.

[4] S. Tanabe and K. Kimura, "Importance of air movement for thermal comfort under hot and humid conditions," Proc. 2nd ASHRAE Far East Conf. Air Cond. Hot Clim. (Kuala Lumpur: Malaysia) p 95-103, 1989.

[5] Y. Fulpagare and N. Agrawal, "Experimental investigation on room air flow pattern \& thermal comfort quantification," Int. J. Eng. Sci. Emerg. Technol. IJESET, vol. 6, no. 1, pp. 120-132, 2013.

[6] P. Wargocki, "The effects of ventilation in homes on health," Int. J. Vent., vol. 12, no. 2, pp. 101-118, 2013.

[7] X. Liu, X. Lv, Z. Peng, and C. Shi, "Experimental study of airflow and pollutant dispersion in cross-ventilated multi-room buildings: Effects of source location and ventilation path," Sustain. Cities Soc., vol. 52, p. $101822,2020$.

[8] K.C. Chung and S.P. Hsu, "Effect of ventilation pattern on room air and contaminant distribution,” Build. Environ., vol. 36, no. 9, pp. 989-998, 2001 .

[9] X. Liu, X. Wu, L. Chen, and R. Zhou, "Effects of internal partitions on flow field and air contaminant distribution under different ventilation modes," Int. J. Environ. Res. Public Health, vol. 15, no. 11, p. 2603 2018.

[10] P. Heiselberg, K. Svidt, and P.V. Nielsen, "Characteristics of airflow from open windows," Build. Environ., vol. 36, no. 7, pp. 859-869, 2001.

[11] S. Hawendi and S. Gao, "Investigation of opening positions on the natural ventilation in a low-rise building by CFD analysis," Int. Conf. Fluid Flow, Heat Mass Transf. (Ottawa: Canada) pp. 151(1-7), 2016

[12] Izudinshah, "Opening Design and Position Effect on Building Natural Stack Effect and Cross Ventilation,” Int. J. Eng. Tech. Res., vol. 5, no. 1, pp. 13-22, 2016.

[13] H. Sacht and M.A. Lukiantchuki, "Windows size and the performance of natural ventilation," Procedia Eng., vol. 196, pp. 972-979, 2017.

[14] T. Chen, Z. Feng and S.J. Cao, "The effect of vent inlet aspect ratio and its location on ventilation efficiency," Indoor Built Environ., vol. 29, no. 2, pp. 180-19, 2020.

[15] S.C. Hu, Y.Y. Wu, and C.J. Liu, "Measurements of airflow characteristics in a full-scale clean room," Build. Environ., vol. 31, no 2, pp. 119-128, 1996

[16] W.F.M. Yusoff, "The effects of various opening sizes and configurations to air flow dispersion and velocity in cross-ventilated building," J. Teknol., vol. 82, no. 4, pp. 17-28, 2020. 